\title{
Perinatal outcome in meconium-stained amniotic fluid at term: a single center prospective study
}

\author{
Vandana Mohapatra $^{1 *}$, Sujata Misra ${ }^{1}$, Tapas Ranjan Behera ${ }^{2}$
}

\begin{abstract}
${ }^{1}$ Department of Obstetrics and Gynecology, Fakir Mohan Medical College and Hospital, Balasore, Odisha, India ${ }^{2}$ Department of Community Medicine, Sriram Chandra Bhanj (SCB) Medical College and Hospital, Cuttack, Odisha, India
\end{abstract}

Received: 29 November 2020

Accepted: 10 December 2020

\author{
*Correspondence: \\ Dr. Vandana Mohapatra, \\ E-mail: mohapatravandana@yahoo.in
}

Copyright: () the author(s), publisher and licensee Medip Academy. This is an open-access article distributed under the terms of the Creative Commons Attribution Non-Commercial License, which permits unrestricted non-commercial use, distribution, and reproduction in any medium, provided the original work is properly cited.

\begin{abstract}
Background: The presence of meconium-stained amniotic fluid is a sign of fetal compromise and is associated with increased perinatal morbidity. The objective of this study was to determine the perinatal outcome in pregnant women at term with meconium-stained amniotic fluid (MSAF) and compare it with the outcome associated with clear liquor.

Methods: A prospective observational, study was conducted in the department of obstetrics and gynecology, VIMSAR, Burla from January, 2013 to June, 2013. Pregnant women with singleton pregnancy, cephalic presentation at term were included in the study. Total 135 cases of MSAF (study group) were compared with 165 randomly selected controls with clear liquor. Outcome measures were fetal heart rate (FHR) abnormality, mode of delivery, Apgar score, neonatal intensive care unit (NICU) admission, diagnosis of meconium aspiration syndrome (MAS), birth asphyxia and neonatal death. Statistical analysis was done by using the mean and Chi-square test with or without Yates' correction.

Results: The mean gestational age for meconium staining in the present study was $40.31 \pm 0.48$ weeks. Caesarean section was the most common mode of delivery in MSAF group whereas vaginal delivery was most common in control group. Significantly higher number of babies in the study group required NICU admissions. The incidence of MAS and birth asphyxia too was statistically higher among babies born to study group as compared to control group. Conclusions: MSAF has significant adverse effect on the perinatal outcome, as it increases the caesarean section rates, NICU admissions, MAS and birth asphyxia.
\end{abstract}

Keywords: Amniotic fluid, Fetal distress, Meconium, Perinatal outcome, Term pregnancy

\section{INTRODUCTION}

The presence of MSAF is a serious sign of fetal compromise and is associated with increased perinatal morbidity and mortality. ${ }^{1} \mathrm{MSAF}$ occurs in approximately 15 to $20 \%$ of term pregnancies. The incidence of MSAF increases with gestational age and is approximately 23$52 \%$ after 42 weeks of gestation. ${ }^{2}$ As most babies with MSAF are 37 weeks or older, it suggests physiological maturation of fetal autonomic nervous system. It may also indicate an acute or chronic hypoxic event, thereby suggesting fetal compromise. ${ }^{3}$ Factors resulting in in- utero passage of meconium are placental insufficiency, maternal hypertension, pre-eclampsia, oligohydramnios or maternal drug abuse (tobacco, cocaine). ${ }^{4}$ Obstructed labour, induced labour and longer duration of labour were other independent factors associated with an increased likelihood of meconium-stained liquor at term. ${ }^{5}$

There is increased risk of respiratory distress in neonates born through MSAF. Meconium passage can predispose to aspiration of meconium and resultant inflammatory pneumonitis, surfactant inactivation, and mechanical airway obstruction. ${ }^{6}$ Meconium aspiration syndrome 
(MAS) results from meconium aspiration during intrauterine gasping or during the first few breaths. About one-third of infants with MAS require intubation and mechanical ventilation.

Improved antenatal care, intrapartum monitoring and amnioinfusion have resulted in reduced stillbirths and better neonatal outcome in recent years. However, in developing nations, MAS still accounts for about $10 \%$ of all cases of respiratory failure with $39 \%$ mortality rate. ${ }^{7}$ Therefore, the present study was undertaken with the objective of determining the perinatal outcome in term deliveries associated with MSAF and comparing it with the outcome associated with clear liquor.

\section{METHODS}

This prospective observational, hospital-based study was conducted in the Department of Obstetrics and Gynecology, VIMSAR, Burla, India during January, 2013 through June, 2013.

Pregnant women between 37 to 42 weeks of gestation with singleton pregnancy and cephalic presentation who were admitted to the labour ward were taken up for study. Women presenting at first stage of labour were selected if they met the inclusion criteria. Prior informed consent was taken from all the study subjects. MSAF was detected after spontaneous or artificial rupture of membranes. Pregnant women with MSAF were recruited as cases, whereas those with clear liquor constituted the control group. The exclusion criteria were gestational age less than 37 weeks, previous caesarean section, multiple pregnancy, non-cephalic presentation, fetal congenital malformation, intrauterine fetal death and women presenting to the labour ward at second stage of labour. Total 135 cases with MSAF were selected and compared with 165 randomly selected controls.

Detailed personal and reproductive histories including maternal high-risk factors were noted. Women were followed up during labour and childbirth. Fetal heart rates were monitored by intermittent auscultations. On detection of any fetal heart rate abnormality or MSAF, further monitoring was done by continuous electronic fetal monitoring. The course of labour, any intrapartum complications including fetal heart rate (FHR) abnormality, the mode of delivery and the neonatal outcome were recorded for every woman. Outcome measures taken were FHR abnormality, mode of delivery, Apgar score at 1 minute and at 5 minutes, NICU admission, diagnosis of meconium aspiration syndrome (MAS), hypoxic ischemic encephalopathy and neonatal death. These variables were observed and compared among the two groups.

Length of gestation was estimated based on the date of last menstrual period or from first trimester ultrasound. FHR abnormality was detected by cardiotocograph (CTG). The FHR tracing was classified as normal, suspicious or abnormal according to NICE guidelines. Birth weight $<2500 \mathrm{gm}$ was taken as low birth weight. Meconium aspiration was confirmed by presence of meconium below the vocal cords on laryngoscopic examination of neonates. MAS was defined as a respiratory distress that develops shortly after birth, with radiographic evidence of aspiration pneumonitis in the presence of MSAF.

Study was approved by Institutional Ethics Committee. The data collected were compiled in Microsoft excel 2010 software. Data were analyzed using the mean and Chi-square test with or without Yates' correction to compare and summarize relevant outcomes. $\mathrm{P}$ value $<0.05$ was considered as statistically significant.

\section{RESULTS}

Total 300 pregnant women at 37 completed weeks of gestation with singleton pregnancy and cephalic presentation were enrolled in the study. Of these, 135 had MSAF while rest165 had clear liquor. The mean age of pregnant women with MSAF was $23.35 \pm 3.42$ years. Out of these 300 pregnant women, $196(66.67 \%)$ were detected at 37-40 weeks of gestation, $92(30.61 \%)$ at $>40$ 42 weeks, and $12(2.72 \%)$ at $>42$ weeks of gestation. The mean gestational age for meconium staining in the present study was $40.31 \pm 0.48$ weeks. Total 147 women had spontaneous onset of labour, rest 153 underwent induction of labour. The common indications for induction were premature rupture of membranes, postdated pregnancy, gestational hypertension and preeclampsia.

Rate of abnormal FHR pattern, mode of delivery, one minute and five-minute Apgar score, NICU admission, meconium aspiration syndrome, birth asphyxia and neonatal death were observed and compared among cases and control (Table 2 and 3). Out of 300 women, 169 $(56.33 \%)$ had spontaneous vaginal delivery, $13(4.33 \%)$ had instrumental delivery and 118 (39.33\%) underwent lower segment caesarean section. Abnormal fetal heart rate pattern was observed in $28.89 \%$ of women with MSAF. Caesarean section was the most common mode of delivery $(58.52 \%)$ in the study (MSAF) group whereas vaginal delivery was the most common mode in the control group. In as many as $35(44.30 \%)$ cases who were delivered by caesarean section in the study group, fetal distress (abnormal FHR pattern on CTG) was the indication for LSCS. The mean birth weight of babies in the study group was $2.89 \pm 0.44 \mathrm{~kg}$ and in the control, group was $2.80 \pm 0.69 \mathrm{~kg}$. Three babies in the study (MSAF) group had five-minute Apgar score of $<4$, while 10 babies had a five-minute Apgar score of 4-7. Abnormal fetal heart rate pattern was observed in all cases in the study group whose babies had poor one minute and 5-minute Apgar scores $(<7)$ at birth.

As compared to controls, significantly higher number of babies in the study group required NICU admissions. Out 
of 27 babies in the study group which required NICU admission, 25 had poor Apgar scores at birth. The incidence of meconium aspiration syndrome and birth asphyxia was statistically higher among babies born to study group as compared to control group. There were three neonatal deaths which occurred in the meconiumstained amniotic fluid group. The deceased babies had one-minute Apgar score of $<4$ and had developed MAS and severe hypoxic-ischemic encephalopathy during NICU admission.

Table 1: Comparison of study and control groups with respect to maternal age, parity, gestational age and antepartum complications.

\begin{tabular}{|c|c|c|c|}
\hline Parameters & Cases $(n=135)(\%)$ & Control group $(n=165)(\%)$ & P value \\
\hline \multicolumn{4}{|l|}{ Maternal age (Year) } \\
\hline$<20$ & $10(7.41)$ & $13(7.88)$ & \multirow{3}{*}{0.631} \\
\hline $20-30$ & $98(72.59)$ & $126(76.36)$ & \\
\hline$>30$ & $27(20)$ & $26(15.76)$ & \\
\hline \multicolumn{3}{|l|}{ Parity } & \multirow{4}{*}{0.581} \\
\hline Primigravida & $101(74.81)$ & $129(78.18)$ & \\
\hline Second gravid & $22(16.30)$ & $20(12.12)$ & \\
\hline Third or more gravid & $12(8.89)$ & $16(9.70)$ & \\
\hline \multicolumn{3}{|l|}{ Gestational age (weeks) } & \multirow{4}{*}{0.0001} \\
\hline $37-40$ & $56(41.48)$ & $140(84.85)$ & \\
\hline$>40-42$ & $68(50.37)$ & $24(14.55)$ & \\
\hline$>42$ & $11(8.15)$ & $01(0.61)$ & \\
\hline \multicolumn{3}{|l|}{ Onset of labour } & \multirow{3}{*}{0.232} \\
\hline Spontaneous onset & $61(45.19)$ & $86(52.12)$ & \\
\hline Induction of labour & $74(54.81)$ & $79(47.88)$ & \\
\hline \multicolumn{3}{|l|}{ Antepartum complications } & \multirow{6}{*}{--} \\
\hline Intrauterine growth restriction (IUGR) & $25(18.52)$ & $10(6.06)$ & \\
\hline Preeclampsia & $21(15.56)$ & $11(8.15)$ & \\
\hline Anemia & $15(11.11)$ & $10(6.06)$ & \\
\hline Pre labour rupture of membranes & $17(12.59)$ & $30(18.18)$ & \\
\hline Oligohydramnios & $26(19.26)$ & $05(3.03)$ & \\
\hline
\end{tabular}

Table 2: Comparison of fetal heart rate pattern, mode of delivery, and Apgar score between cases and controls.

\begin{tabular}{|c|c|c|c|}
\hline Fetal heart rate pattern & Cases $(n=135)(\%)$ & Control group $(n=165)(\%)$ & P value \\
\hline Abnormal & $39(28.89)$ & $10(6.06)$ & $<0.0001$ \\
\hline \multicolumn{4}{|l|}{ Mode of delivery } \\
\hline LSCS & $79(58.52)$ & $39(23.64)$ & $<0.0001$ \\
\hline Spontaneous vaginal delivery & $51(37.78)$ & $118(71.52)$ & $<0.0001$ \\
\hline Instrumental vaginal delivery & $05(3.70)$ & $08(4.85)$ & 0.52 \\
\hline \multicolumn{4}{|l|}{ One-minute Apgar score } \\
\hline$<4$ & $05(3.70)$ & $02(1.21)$ & 0.41 \\
\hline $4-7$ & $20(14.81)$ & $14(8.48)$ & 0.09 \\
\hline$>7$ & $110(81.48)$ & $149(90.30)$ & 0.03 \\
\hline \multicolumn{4}{|l|}{ Five-minute Apgar score } \\
\hline$<4$ & $03(2.22)$ & $01(0.61)$ & 0.52 \\
\hline $4-7$ & $10(7.41)$ & $04(2.42)$ & 0.08 \\
\hline$>7$ & $122(90.37)$ & $160(96.97)$ & 0.03 \\
\hline
\end{tabular}

Table 3: Neonatal outcome.

\begin{tabular}{|llll|}
\hline Neonatal outcome & Cases $(\mathbf{n = 1 3 5})(\boldsymbol{\%})$ & Control group $(\mathbf{n}=\mathbf{1 6 5})(\boldsymbol{\%})$ & P value \\
\hline Asymptomatic/routine care & $108(80)$ & $149(90.30)$ & 0.012 \\
\hline NICU admission & $27(20)$ & $16(9.70)$ & 0.012 \\
\hline Meconium aspiration syndrome & $07(5.19)$ & $01(0.61)$ & 0.018 \\
\hline Birth asphyxia & $19(14.07)$ & $10(6.06)$ & 0.02 \\
\hline Neonatal death & $03(2.22)$ & $01(0.61)$ & 0.52 \\
\hline
\end{tabular}




\section{DISCUSSION}

MSAF is a very common finding, occurring in up to $20 \%$ of deliveries at term. ${ }^{4}$ Aspiration of meconium occurs as a result of hypoxia and hypercarbia which act synergistically to stimulate fetal gasping. It can contribute to MAS, representing a leading cause of perinatal death. MSAF is associated with higher incidences of abnormal labor, fetal distress, intervention in delivery and low Apgar score. ${ }^{8}$ The present study determined the perinatal outcome in women with MSAF at term and compared various outcomes with the control group having clear liquor.

The incidence of MSAF in the present study was highest in the age group of 20-30 years. Other studies also observed a similar age incidence of pregnant women with MSAF. ${ }^{8,9}$ There was no significant difference in the age distribution between cases and controls in our study. Majority of women in both study as well as control group were primigravida. The occurrence of meconium staining increases with gestational age. A study on 1500 deliveries to identify predictors of MSAF observed that postdated pregnancy was one of the significant, independent risk factors for MSAF. ${ }^{10}$ About $50 \%$ of our cases had gestational ages of $>40-42$ weeks.

Factors that promote the passage of meconium in utero include placental insufficiency, maternal hypertension, preeclampsia, oligohydramnios, and maternal drug abuse, especially of tobacco and cocaine. ${ }^{7,11}$ Association of preeclampsia with MSAF is caused due to an underlying placental insufficiency which contributes to fetal hypoxia and subsequent meconium passage. Intrauterine growth restriction and preeclampsia together were associated with MSAF in more than $30 \%$ cases in our study.

Most workers showed an association of fetal heart rate abnormalities, low Apgar scores and low arterial cord $\mathrm{pH}$ with MSAF. ${ }^{11,12}$ Our observation showed abnormal fetal heart rate pattern in $28.89 \%$ cases with meconium-stained liquor as compared to only in $6 \%$ women in the control cohort which was statistically significant. Literature review shows very high rates of caesarean section in women with meconium staining of amniotic fluid which is in accordance with our observation. ${ }^{13,14}$ Moreover, the absence of facilities for continuous electronic fetal monitoring and fetal scalp blood $\mathrm{pH}$ monitoring added with the fear of poor neonatal outcome in obstetricians in low resource setting, increases the incidence of operative as well as instrumental delivery. MSAF was associated with significantly high rates of caesarean section even in low-risk pregnancies at term, possibly reflecting a combination of labor dystocia and a lower threshold for obstetric intervention. ${ }^{15}$

MSAF is associated is increased risk of neonatal respiratory morbidity and mortality. Mean Apgar scores were significantly lower in case of meconium staining of liquor. ${ }^{11}$ Also, the proportion of neonates with poor
Apgar scores was higher if thick meconium was present, but not for thin meconium. ${ }^{14}$ In the current study, we did not group cases according to grades of meconium staining. Though one minute and five-minute Apgar scores were lower in our MSAF group as compared to the clear liquor group, the difference was not statistically significant. Similar small differences were noted in meconium and non-meconium groups with regard to arterial $\mathrm{pH}$ and Apgar scores in one study. ${ }^{16}$ However, Sori et al observed very high incidence of MAS; and the rate of low first minute Apgar score was higher despite higher rate of operative deliveries. ${ }^{17}$ Similar to our study, other studies also reported very high rate of NICU admissions ranging up to $20 \%$.,11

MAS results from aspiration of meconium during intrauterine gasping or during the first few breaths. Meconium in the alveoli can cause surfactant inactivation and induce inflammation leading to chemical pneumonitis. ${ }^{7}$ MAS was diagnosed in 5\% cases in MSAF group in our study which is in accordance with the Mundhra et al study. ${ }^{3}$ However, other studies reported higher rates of MAS. ${ }^{11,17}$ The risk of perinatal death is increased five to seven-fold when a thick meconium is present at the onset of labour. ${ }^{5}$ All the neonatal deaths in our study were due to MAS leading to birth asphyxia. Neonatal respiratory morbidity which includes respiratory distress syndrome, transient tachypnea of the newborn, or need for ventilatory support was increased in the presence of meconium staining. ${ }^{15}$

\section{CONCLUSION}

MSAF is a common occurrence during labour. MSAF has significant adverse effect on the perinatal outcome, as it increases the caesarean section rates, NICU admissions, meconium aspiration syndrome and birth asphyxia. Proper intrapartum care including continuous electronic fetal monitoring, timely obstetric intervention followed by appropriate neonatal care is essential to alleviate the adverse outcome associated with it.

\section{Funding: No funding sources Conflict of interest: None declared \\ Ethical approval: The study was approved by the Institutional Ethics Committee}

\section{REFERENCES}

1. Maymon E, Chaim W, Furman B, Ghezzi F, Shoham Vardi I, Mazor M. Meconium-stained amniotic fluid in very low risk pregnancies at term gestation. Eur $\mathrm{J}$ Obstet Gynecol Reprod Biol. 1998;80:169-73.

2. Ross MG. Meconium aspiration syndrome-more than intrapartum meconium. N Engl J Med. 2005;353(9):946-8.

3. Mundhra R, Agarwal M. Fetal outcome in meconium-stained deliveries. J Clin Diagnostic Res. 2013;7(12):2874-76. 
4. Shaikh EM, Mehmood S, Shaikh MA. Neonatal outcome in meconium-stained amniotic fluid-oneyear experience. J Pak Med Assoc. 2010;7(9):71114.

5. Addisu D, Asres A, Gedefaw G, Asmer S. Prevalence of meconium-stained amniotic fluid and its associated factors among women who gave birth at term in Felege Hiwot comprehensive specialized referral hospital, North West Ethiopia: a facility based cross-sectional study. BMC Preg Childbirth. 2018;18:429.

6. Klinger MC, Kruse J. Meconium aspiration syndrome: pathophysiology and prevention. J Am Board Fam Pract. 1999;12(6):450-66.

7. Swarnam K, Soraisham AS, Sivanandan S. Advances in management of meconium aspiration syndrome. Int J Pediatr. 2012;7.

8. Bhatia P, Ela N. Fetal and neonatal outcome of babies in meconium-stained amniotic fluid and meconium aspiration syndrome. J Obstet Gynecol India. 2007;57(6):501-04.

9. Sandhu SK, Singh J, Khura H, Kaur H. Critical evaluation of meconium staining of amniotic fluid and foetal outcome. J Obstet Gynecol India. 1993;43:528-53.

10. Naveen S, Kumar SV, Ritu S, Kushia P. Predictors of meconium-stained amniotic fluid: a possible strategy to reduce neonatal morbidity and mortality. J Obstet Gynecol India. 2006;56:514-7.

11. Patil KP, Swamyy MK, Samatha K. A one-year cross sectional study of management practices of meconium-stained amniotic fluid and perinatal outcome. J Obstet Gynecol of India. 2006;56(2):12830 .
12. Oyelese Y, Culin A, Ananth CV, Kaminsky LM, Vintzileos A, Smulian JC et al. Meconium-stained amniotic fluid across gestation and neonatal acid base status. Obstet Gynecol. 2006;108:345.

13. Edmond NM, Philip NN, Julienne SN, Julius SD, Evelyn $M$ et al. Perinatal Outcome in Term Pregnancies with Meconium-Stained Amniotic Fluid in Two Referral Hospitals of Yaoundé- Cameroon. Biomed J Sci Tech Res. 2018;2(2).

14. Saunders K. Should we worry about meconium? A controlled study of neonatal outcome. Trop Doct. 2002;32(1):7-10.

15. Hiersch L, Krispin E, Aviram A, Wiznitzer A, Yogev Y, Ashwal E. Effect of Meconium-Stained Amniotic Fluid on Perinatal Complications in Low-Risk Pregnancies at Term. Am J Perinatol. 2016;33(04):378-84.

16. Becker S, Solomayer E, Dogan C, Wallweiner D, Fehm T. Meconium-Stained Amniotic fluidperinatal outcome and obstetrical management in a low-risk suburban population. Eur J Obstet Gynecol Reprod Biol. 2007;132(1):46-50.

17. Sori DA, Belete A, Wolde M. Meconium-Stained Amniotic Fluid: Factors affecting Maternal and Perinatal Outcomes at Jimma University Specialized Teaching Hospital, South West Ethiopia. Gynecol Obstet. 2016;6(8):394.

Cite this article as: Mohapatra V, Misra S, Behera TR. Perinatal outcome in meconium-stained amniotic fluid at term: a single center prospective study. Int J Reprod Contracept Obstet Gynecol 2021;10:107-11. 